\title{
The Charles Sturt University Remote Telescope Project
}

\author{
David H. McKinnon ${ }^{1 *}$
}

\begin{abstract}
This paper briefly documents: the history of the Charles Sturt University Remote Telescope Project, from its inception in 1994; its achievements through its impact on students and participating teachers both nationally and internationally; and, its production of research papers in an environment designed to encourage the engagement of students. Its development was based on problem solving processes at a time when both the hardware and software were lacking and teachers more generally were afraid of getting involved. Collaborative problem solving amongst hardware, software and networking engineers working with science-education specialists occurred in a cooperative environment, where the latter was driven by the desire to improve science education more broadly than just solely in the astronomical domain.

\section{Keywords}

science education; teacher professional learning; remote control telescopes

${ }^{1}$ Edith Cowan Institute for Education Research, Edith Cowan University, Joondalup, WA, Australia

*Corresponding author: d.mckinnon@ecu.edu.au
\end{abstract}

\section{Introduction}

After observing for many years by peering through the off-axis guider of a 10" Newtonian telescope while imaging, the author developed an interest in controlling telescopes after acquiring and reading the seminal text by Trueblood and Genet 1985 in 1986. After all, here was a way to avoid a sore back endured in the freezing cold to get images of nebulae and galaxies. An advertisement seen in Sky and Telescope in 1988 for the SBIG ST4 CCD camera (selling then for US\$12,500) sowed the seeds of an idea for an educational telescope.

The Internet arrived in Australia in 1994, the year in which the author had been appointed, and paid, as the Course Coordinator for the Cosmology Distinction Course offered by the New South Wales (NSW) Board of Studies for Education. This course had been commissioned by the Board as a way to challenge and extend gifted and talented students in their final years of high school
(McKinnon and Nolan, 2000) and was offered for the first time in 1994. In 1995, with his new-found "wealth", the author purchased a Starlight Xpress CCD camera that output the image data at high speed through a parallel port connection to a computer. After seeing M42 in black and white taken with an unsilvered mirror and a 10 second exposure at $\mathrm{F} / 5$, the author was convinced that many things were possible.

The author's immediate reaction was to start to roboticise his 10" Newtonian reflector which, at that stage, had a synchronous electric motor drive only on the polar axis with manual controls on the declination axis. Stepper motors were acquired and the mount machined to accommodate them.

Programming these took a bit longer and was never completed because, in late 1996, the author read an article in New Scientist leading him to consider how long "this whole process" would take as a sole venture. The answer was about 25 years!

Consequently, using the Cosmology Distinction 
Course money, a Meade 12" LX200 telescope shown in Figure 1 with all the bells and whistles was purchased and shipped over the high seas from California to Australia in mid 1996. The telescope was eventually controlled using The Sky IV(C) and TPoint (c) courtesy of Software Bisque with RoboFocus added later. The author made the decision not to use the Software Bisque Remote Astronomy Software that was being employed to control the Mount Wilson 24" telescope run by Telescopes in Education. The main reason for this was the cost to each individual end-user, a fee that was judged to be beyond the resources of any Australian elementary school or indeed a high school science department and hence be a potential, and major, barrier to implementation.

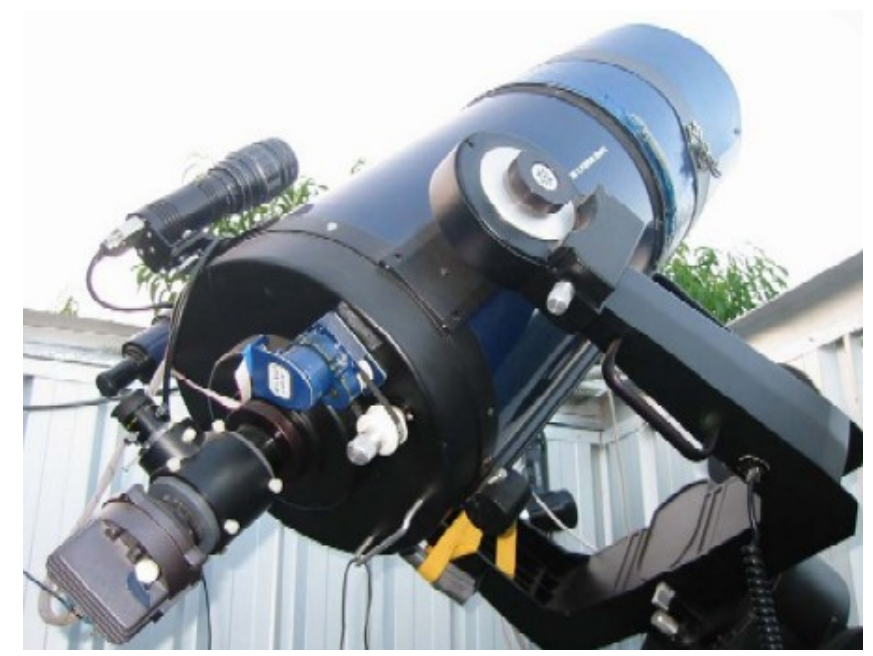

Figure 1. LX200, Starlight Xpress CCD cameras, RoboFocus, Taurus Tracker

During 1997, the author designed a small roll-off roof observatory for the new 12" telescope, and had it built by a local garden-shed manufacturer. Subsequently, metal louvers were fitted to the outside as an efficient form of passive cooling. A small fan with a thermostat provided active control of the interior temperature in the hot summer months. The remaining, and significant, problems all related to how the telescope and parallel-port camera could be controlled, at low cost, over the Internet by the end user. In discussion with staff in the Division of Information Technology at Charles Sturt University (CSU), who had become entranced by the project, a solution emerged. A file server was required to run Windows NT (c) with desktop access provided by Citrix (c) software. The server, fitted with an additional parallel port and four serial ports was acquired from IBM at a significantly reduced cost. Control of the camera was achieved by writing routines to bypass the NT kernel to allow the camera output to enter the computer through the parallel port. We achieved full control over the system in early December 1999 when the technical assistant, Andrew Mainwaring, remotely moved the telescope and took an image of the blue sky. It was an uninteresting shade of grey, for obvious reasons.

The author spent the southern hemisphere summer break of 1999-2000 writing the first version of the book "A Journey through Space and Time" while Mainwaring created a website (see: McKinnon and Mainwaring, 2000). The book was, in essence, an instructional manual with lots of screen dumps on how to control the telescope, the camera, and how students could process their images using the Starlight Xpress software. Also included were many astronomy investigation activities designed to address the content of the NSW Elementary School Science and Technology curriculum from a practical perspective. These covered such topics as phases of the Moon, seasons, scale models and the size and scale of the Solar System.

\section{The early years 2000-2002: Early research projects}

At the start of the 2000 academic year, in February, the author made contact with three local schools who agreed to come to an official launch dinner, to undertake the astronomy content and, to attempt control from their schools. The launch dinner was hosted by the University's Vice Chancellor (President) Professor Cliff Blake, was also attended by various notaries, the teachers and principals of the three participating schools. Professor Fred Watson, Astronomer in Charge, Anglo-Australian Observatory traveled to the University to "launch" the project and to give the after-dinner speech. During the launch, control of the telescope was demonstrated and, with audience participation, 
images of the Moon acquired before an un-forecast shower of rain put an end to observing.

Nonetheless, it was all very jolly as were the dinner and speeches. Soon afterwards, a professional learning day was scheduled for the participating teachers during which they controlled the telescope and experimented with image processing. In addition, they were introduced to the investigations in the book.

Despite the author's best efforts in this small Pilot Study, there was a total absence of any attempt by the teachers either to use the astronomy related curriculum materials or the telescope. Subsequent interviews with the teachers revealed that not only did they know nothing of the astronomy in the elementary school curriculum (they had never taught it "this way"), they were also afraid of using computers for something other than word processing much less control a telescope over the Internet. It was apparent that there was a major professional development issue that had to be addressed simultaneously with the teachers' fears in the IT domain. Thus, this "disaster" provided a clear track for a more formal research project and for better design of the educational materials.

Consequently, during late 2000, the author employed a professional educational designer (Dr. Helen Geissinger), and a retired school principal (Dr. Des Wilsmore) to provide critical feedback on the design and layout of the book and its contents. In addition, while the author was teaching a quantitative research methods course, the interest of one teacher-education student was piqued (Lena Danaia). She wished to undertake some research for her Bachelor's thesis. A local artist (Shane Summerton) was contracted to provide quirky cartoons to illustrate the transformed text. Version 2, shown in Figure 2, was printed in colour. An additional camera with IR illuminator was placed in the observatory to provide the end user with feedback that it was them who was moving the telescope. An all-sky camera was built and added to the observatory so that on problematic evenings we could hunt for holes in the cloud to obtain images. A second CCD camera was added
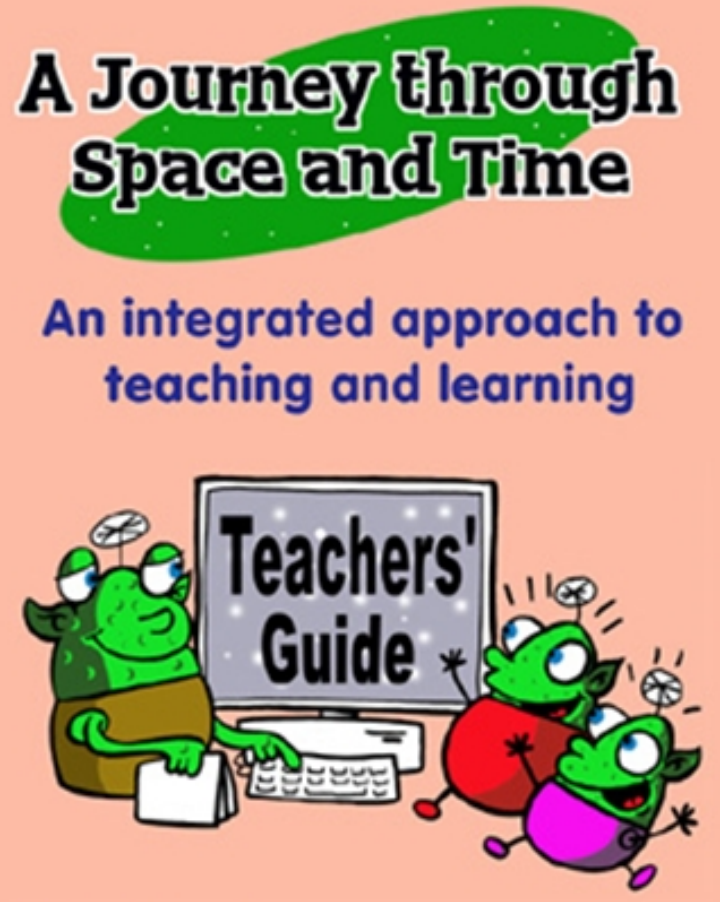

Charles Sturt University

Remote Telescope

Australia

David H McKinnon Project Manager

Figure 2. Version 2 of the 189 page text A Journey through Space and Time

and piggy-backed on the telescope with a $135 \mathrm{~mm}$ lens to give some sense of context for the prime-focus images of the 12" telescope. A small research grant from CSU funded the research project with four classrooms in three widely separated schools. The closest school was $150 \mathrm{~km}$ away and the furthest $600 \mathrm{~km}$ from the university.

We conducted one intense professional development day for the four participating teachers 10 weeks before the intended implementation date. This was followed by regular email and telephone contact by the author to check progress and to answer any questions about the materials. The intention of this approach was to allow adequate time for the participating teachers to read the materials and to become familiar with the investigations as well as to have private practice sessions to control the telescope online with the 
author present at the observatory to provide support, both technical and moral. The ongoing support provided during this period was central to this project's success.

As it turned out, one class had already "done astronomy" earlier in the year and the teacher was only interested in his class controlling the telescope to get images and to process them. The other three classes undertook all of the 34 investigations in the book over a 10-week term as well as controlling the telescope in evening sessions to which parents were invited. The author was invited to the closest school where two classes were undertaking the project. The visit involved meeting with the students in the two Grade 5 classes and giving a talk with demonstrations.

Danaia 2001 investigated the impact of this project on students' alternative scientific conceptions and the extent to which these were changed. Her results demonstrated that it was not the control of the telescope or the image processing per se that increased students' content knowledge or reduced their alternative conceptions. Rather, it was the careful implementation of the investigations using the Conceptual Change Model (Stepans, 1996) that redressed their alternative conceptions.

Indeed, our data showed that there was minimal change in the content knowledge or the alternative conceptions of the students who had "done their astronomy unit" in the first school term. Figure 3 shows one group deeply engaged with what they are doing with the telescope while their teacher watches from the periphery. They were motivated by the control that they had over the devices. However, there were highly significant positive changes evident in the other three classes with significant gains in their content knowledge and significant reductions in their alternative conceptions. All classes were enthused by the online sessions where the author was at the other end communicating with them while they controlled the telescope.

During the online sessions, they wanted images of the Moon, the planets and other Solar System objects such as asteroids that they had been



Figure 3. Students at the school who had "done astronomy controlling telescope and cameras

studying in class (McKinnon and Geissinger, 2002; McKinnon et al., 2002). One Year 5 student, in seeking an image of Messier 83, wrote as his reason for getting the image "I have seen lovely colour pictures of this galaxy on the Internet. But, I want one all of my own." (student MCD). We concluded that remote control of the telescope was an important motivating factor while students undertook the astronomical investigations dictated by the requirements of the elementary school curriculum.

During the first half of 2002, the author went to The Netherlands on sabbatical. It became apparent that the Dutch high-school students (Grade 10) possessed as many alternative conceptions as the elementary students in Australia. Indeed, many were identical. Many Dutch science teachers chose to become involved with the project. The materials contained in A Journey through Space and Time were adapted and translated for implementation by teachers in the eastern part of the country (McKinnon, 2002). Many teachers repeated these online sessions each year with new classes of students until the author moved universities in July 2014.

While in The Netherlands, the author also met a contingent of Canadian educators from New Brunswick. One administrator wanted all of the 
Middle Schools in the province to become involved. A visit to Canada in late 2002 cemented the relationship that continued for 10 years. A further Canadian teacher, Rob Edwards at West Kildonan Collegiate in Winnipeg, Manitoba, made contact just before Christmas having found our telescope website. He later confessed that it had been his goal to get "one or two images to enliven" his science classes. Little did he then know that over the next 12 years he would write school-based astronomy subjects for his students, mostly based on the materials contained in A Journey through Space and Time, win an outstanding science teacher provincial award and have his students win prizes at science fairs. These events led to larger projects enacted during the middle years of the project 2003-2009.

\section{Research Projects and Events in the Middle Years 2003-2008}

On the basis of Danaia's findings in 2001 and the publications that flowed from it, the author was invited to submit a large grant proposal to the Federal Department of Education, Science and Training in 2003 to investigate the impact of remote observing on the learning of high school students in Grades 7-9. In this project, the materials were adapted for the high-school science curriculum in four Australian educational jurisdictions: NSW, Queensland, Victoria and the Australian Capital Territory. The remote telescope project had to be massively scaled up to deliver access in 2004 to over 2000 students, 101 classes in 40 schools in the same school term. Two books were prepared: one for students and one for teachers. These guided both groups on how to undertake investigations. The project led to the generation of an enormous data set containing students' attitudes towards the science they experienced in their schools, their content knowledge, their alternative conceptions and, their ability to express scientific ideas. Danaia was enticed to return from her teaching career to undertake her Doctoral Studies and to be the project manager. She employed a repeated-measures mixed-methods research design to investigate the impact of the project on students. Her thesis (Danaia, 2006), submitted for examination in early 2007, has given rise to many journal articles with Danaia as the lead author (e.g., Danaia and McKinnon (2007)). The final report of the project to the federal department was delivered in June 2005 (McKinnon and Danaia, 2005).

In June 2004, we streamed the Transit of Venus live on the Internet from Charles Sturt University. Demand for the live feed was so high because of suspect weather conditions elsewhere on the eastern seaboard that it brought the University network to its knees. Limited bandwidth into Sydney from the University (34 Megabits/second) meant that the live feed was still being delivered from buffers long after the Sun had set! The community involvement in this event was enormous.

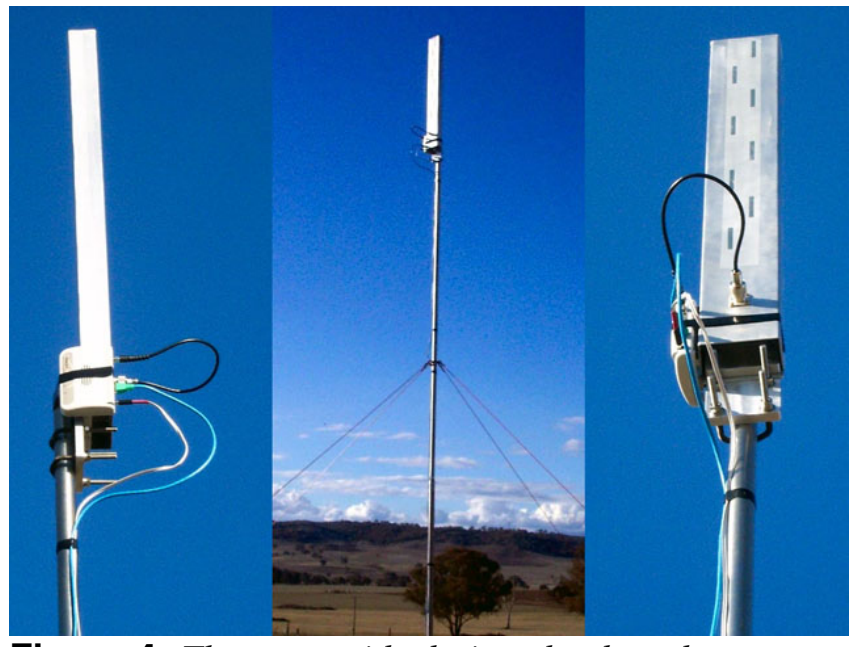

Figure 4. The waveguide designed to broadcast a horizontal beam

A specially designed waveguide, shown in Figure 4, was built by a member of a local amateur Wi-Fi group in Bathurst (Bathurst Wireless), to transmit data from a hilltop $10 \mathrm{~km}$ out of the city to the roof of a government building where a parabolic receiver pumped the signal into a cable networked to the Land and Information Centre's supercomputer network before shunting it to the University over a fibre-optic link to our web server for distribution to the Internet. Figures 4 and 5 show the peculiar setup, while Figure 6 shows 
images captured during the transit with time marks displayed for online delivery at the bottom right of the images. We could, however, deliver timing accurate to one millisecond using multiple time servers pinged over the Internet and using "Yet Another Time Server" modelling software.

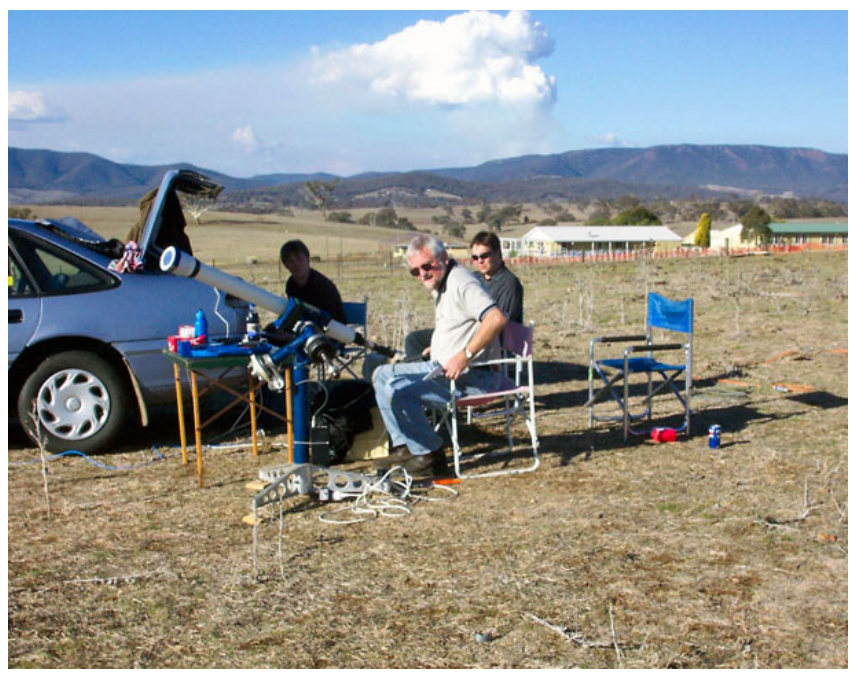

Figure 5. The 3" telescope, camera with the server in the trunk of the car and powered by a $150 \mathrm{~m}$ cable plugged into a garage power point.

Thus, timing of first and second contacts were provided accurate to one millisecond so that the other end of the baseline in the United Kingdom could emulate the historical calculations to get a distance to the Sun. Indeed, the first successful Transit of Venus observations were undertaken from Tahiti in 1769 with Lieutenant James Cook as the ship's commander. Afterwards, he sailed westwards, mapped the entire coast of New Zealand and the east coast of Australia claiming both for the British Crown.

\section{Teacher Education}

During 2005, the author and Danaia reconstructed and delivered a pair of subjects in teacher education that dealt with science and technology. The first subject was tightly focussed on astronomy using it as the domain in which to address the issues of elementary school teachers' science content knowledge, teaching efficacy, and investigatory pedagogical approaches. Figure 4 shows the modelling of the Earth-Moon system

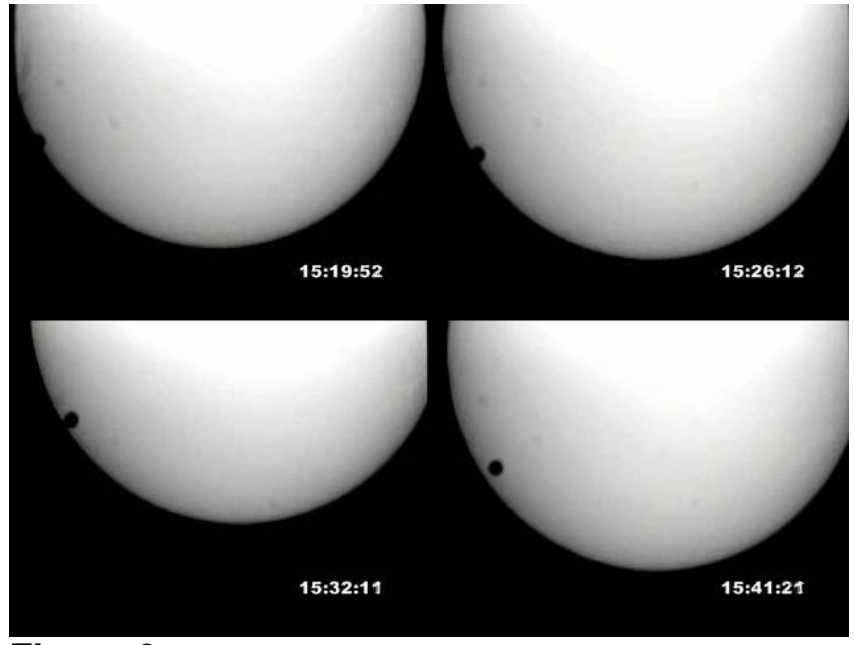

Figure 6. Composite of transit images showing second contact

after the students had dealt with the mathematics of scale models.

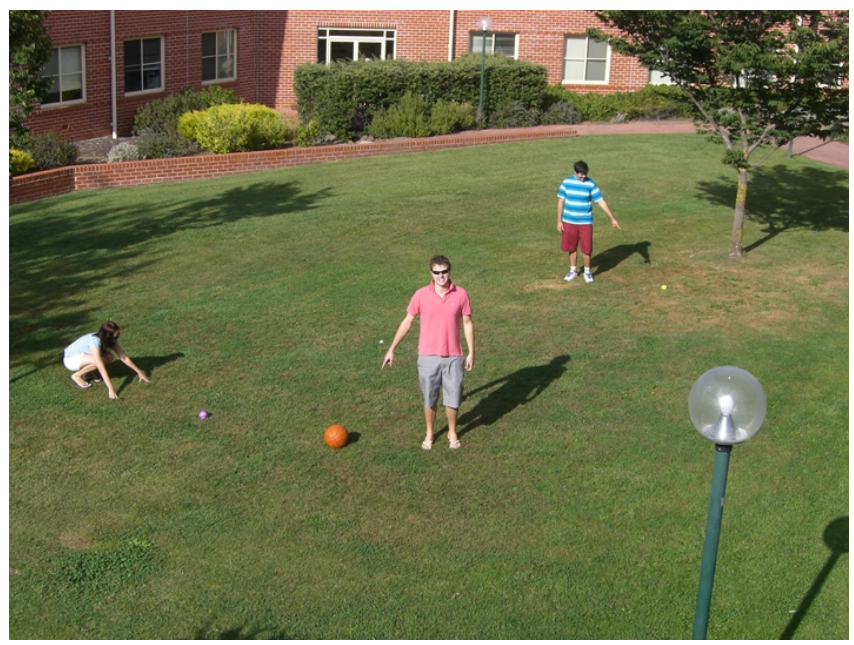

Figure 7. Elementary Teacher Education students showing three scale models of the Earth-Moon system.

We presented our first conference paper on the approach (McKinnon and Danaia, 2005) and were invited by our university to apply for a national tertiary teaching award, which we won in 2006. In 2008, with more data acquired we addressed the five key criteria for the Australian Learning and Teaching Council's Teaching Excellence Award, which we won on our first attempt. In both cases, large cash prizes were gratefully received and with the second one, dinner in the Old Parliament House in the Australian capital, Canberra. Each year, we 
collected more data on the impact of the courses on students' self-efficacy, content knowledge, alternative scientific conceptions out of which emerged a model that can be applied to any elementary teacher education course involving science (McKinnon et al., 2017).

In December 2005, we were invited to take part in the global Mega Conference that started at midnight in Australia, and which rippled around the globe as various institutions showcased their wares in the video conferencing domain. The Chair had a different hat for every participating country. It was great fun. Nick Cross from the Australian Academics Research Network (AARNet) helped provide the infrastructure to integrate the telescope system into an $\mathrm{H} 323$ video conference broadcast to the world. We were nominated as one of the 10 "best performances" with images being acquired from the sky "down under" and broadcast to the world. Figure 7 shows the Chair of the Conference and his assistant with the stream of culturally appropriate hats being delivered as each new presenter came online for the 10-minute presentation.

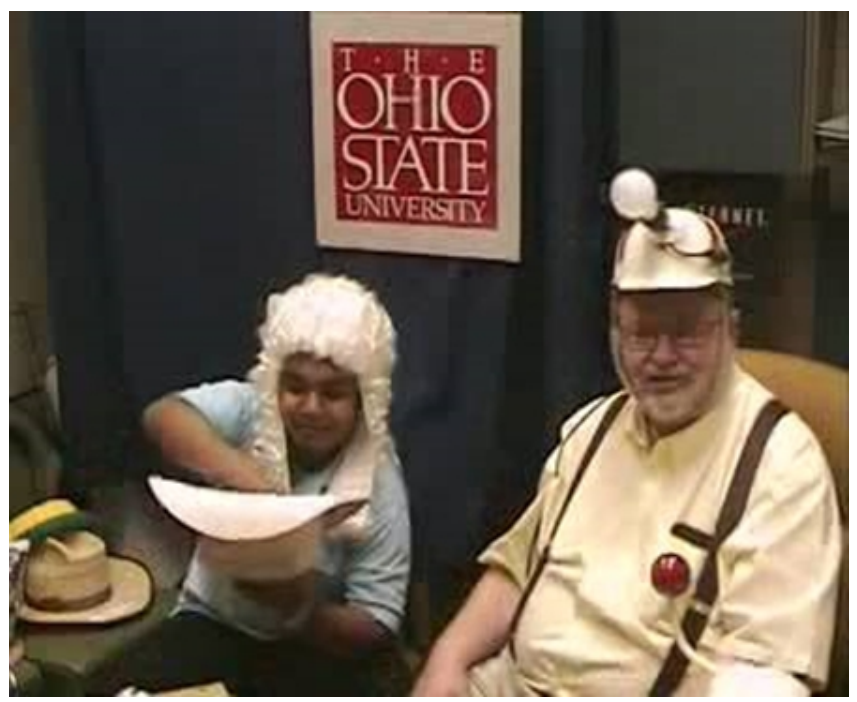

Figure 8. The Chair of the 2005 World Mega Conference hosted by Ohio State University

\section{Student Research Projects}

In NSW, Australia, during 2005, a Grade 10 student undertook an individual investigation on a (potentially) variable star as part of the curriculum requirements for the award of the state's formal School Certificate. This work won him the award for Best Individual Investigation from the NSW Science Teachers' Association and, early the following year, an invitation to present a talk at the National Curriculum Corporation Annual Conference, which paid for his airfares and his accommodation in a five-star hotel in Adelaide, South Australia.

In Canada, Rob Edwards began to require his students to undertake authentic research projects in one of his astronomy subjects. In 2007, one young lady, Alaina Edwards (no relation to Rob), undertook an investigation into another potentially variable star using differential photometry. She acquired Dark Frames, Bias Frames and Flat Fields. She presented her findings at the Manitoba Science Competition in 2008. Of interest was the fact that she was stopped about 10 minutes into her presentation by the judges who confessed that they would need to get someone from the Royal Astronomical Society of Canada (RASC) to assay her paper as they had "no idea what she was talking about". Nervous, she waited while the search for the expert was conducted. When found, she was invited to "start over", which she did.

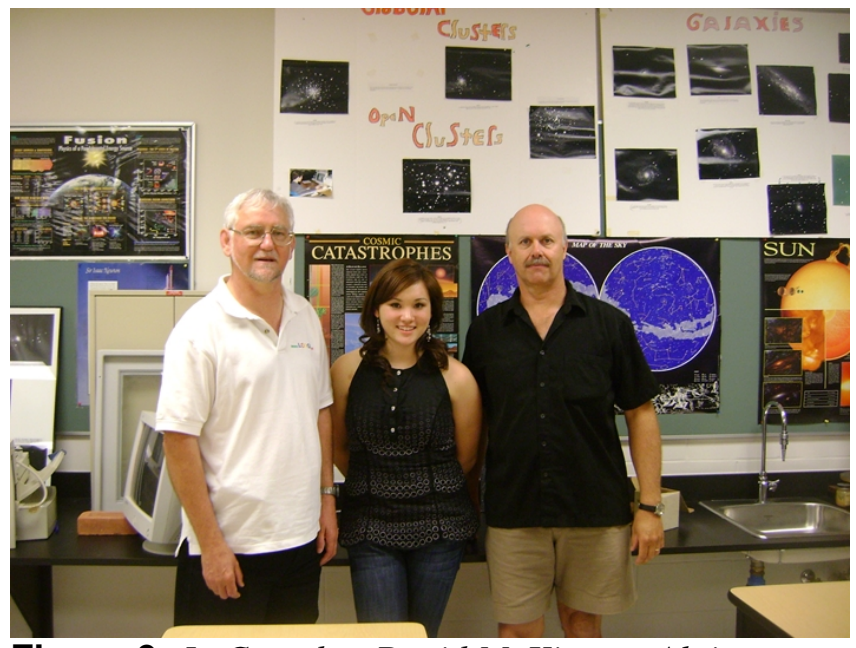

Figure 9. In Canada - David McKinnon, Alaina Edwards, Rob Edwards (left to right) in 2009

She was awarded first prize in the competition and was also awarded the RASC prize for Astronomy 
(a meteorite from an observed fall in Algeria) and a cash prize from the competition. The latter she donated to her school, while the former she cherishes. The RASC invited her to present her paper at a later professional meeting of the Society where one member was overheard commenting to another "Now that is what I call real science". Alaina and her teacher are shown in Figure 6 in the West Kildonan Collegiate science laboratory on a visit by the author in 2009. By that stage, she was in first year at university, still immensely proud of her accomplishment.

In the following year, 2009, another West Kildonan Collegiate student took out a Bronze award for his work on a star he identified as an eclipsing binary. Later literature searches revealed that it had indeed been identified as one in a single paper published in 1930. The teacher, Rob Edwards, was awarded the "Best Science Teacher of 2008" for his brilliant endeavours to engage the students in his classes.

\section{Webcasts}

In July, 2005, we collaborated with the University of Maryland to provide images of NASA's Deep Impact Mission to impact the comet Temple 1. The impactor arrived at the comet two hours before the Australian sunset on July 4. The mission was designed so that the impact could be monitored in the dark from the telescopes in Hawaii. We provided images of the very faint comet (Magnitude 14) to schools in the two weeks leading up to the impact and from two hours after the impact. All images were taken with standardised exposures. Many students remarked on the significant brightening of the comet nucleus after the impact. In total, we provided data comprising thousands of images taken over a period of four weeks.

In November 2006, we broadcast the Transit of Mercury where we delivered two images per second to the Internet. Figure 7 shows one of the images taken with the system not long after sunrise. This method overcame the problems we had encountered with the live feed of the Transit of Venus in 2004.

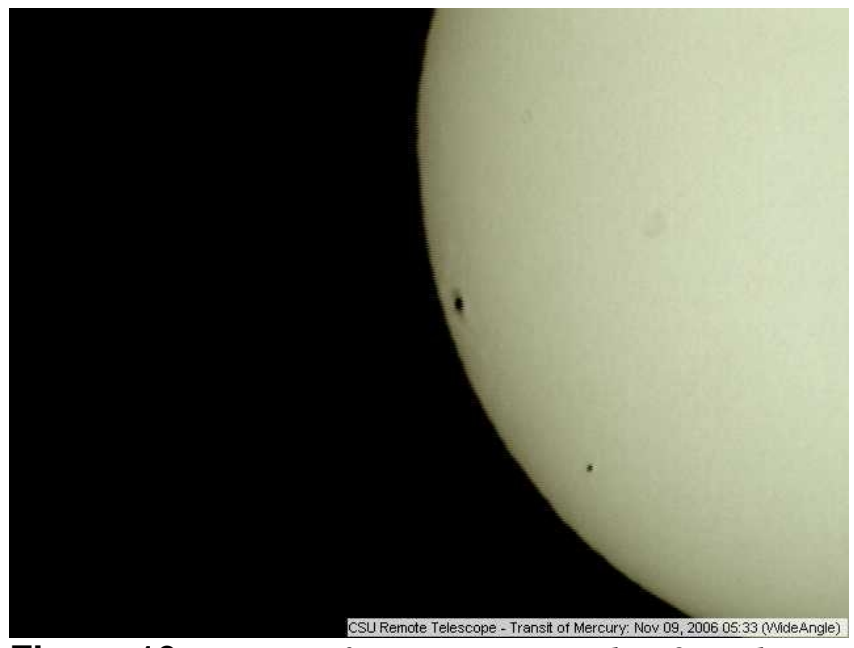

Figure 10. Transit of Mercury, November 9, and sunspot.

The telescope, shown in Figure 8, was quite a sight wrapped in many metres of Aluminium foil to keep it reasonably cool during the heat of the day.

During the transit broadcast, we recorded over 93,000 hits on our website.

In 2007, again using the same method, we broadcast the August 27 total lunar eclipse. Analytics revealed over 190,000 hits during the four-hour broadcast. We also made a video of the entire eclipse collapsed into a three-minute timespan to drive home to teachers and their students that it is not the Earth's shadow that creates the phases of the Moon. This piece of evidence helps the students to understand that their alternative conception is not adequate to explain the gibbous phase thus readying them for the modelling of the actual reason for the phases. The video is distributed with the educational materials.

\section{The later years 2009-2014}

The later years of the CSU Remote Telescope project built on the research and development foundations of the earlier years with an extension into Aboriginal astronomy in the elementary school and a move into robotic observations using the Las Cumbres Observatory 2-metre telescopes in a federally funded research project. In 2009, while on sabbatical at the University of Wyoming, I formed a major liaison with Scott Mecca then living in Sheridan, Wyoming. The liaison 


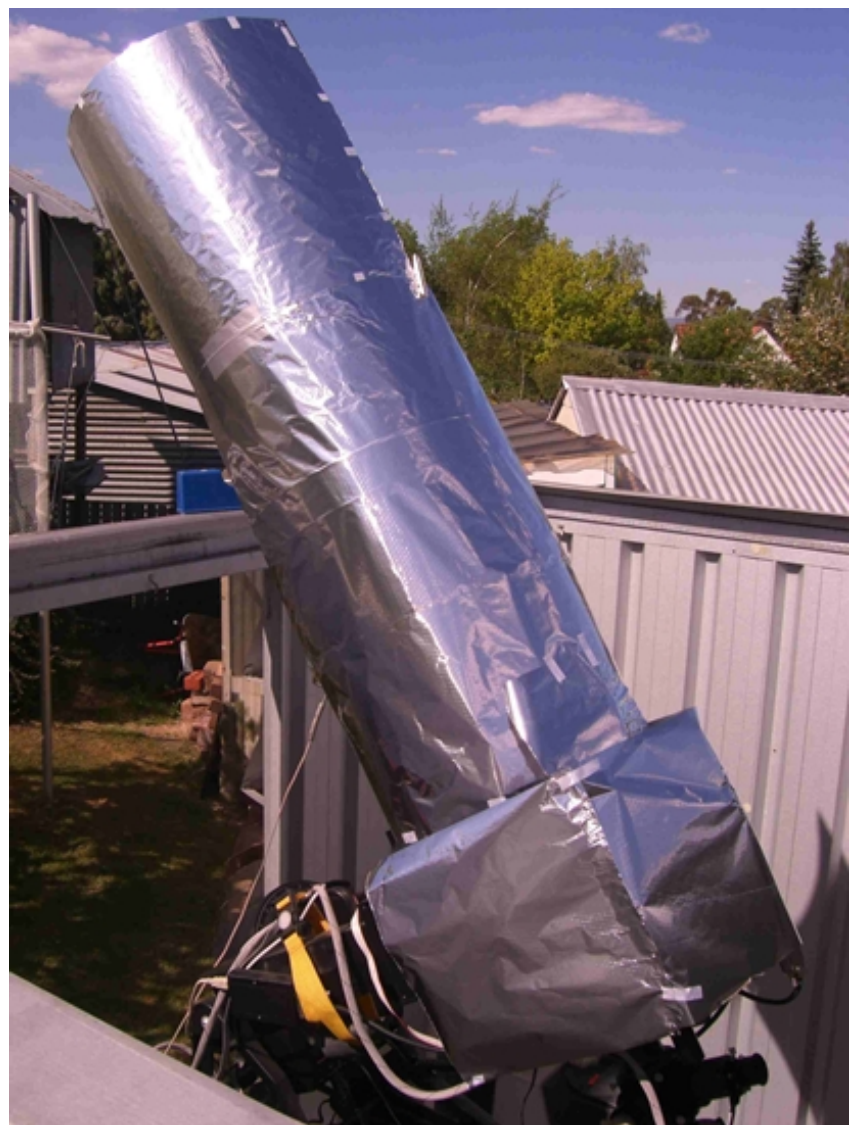

Figure 11. The set-up for the 9th November 2006 Transit of Mercury: Aluminium foil to keep it cool

developed, blossomed, and has allowed Australian elementary-school students to take control of Scott's telescopes in that state as well as another one in Texas. In 2012, the author and Danaia jointly originated the Indigenous Sky Stories project that has now extended to 57 schools, with an additional 12 in Western Australia, all of which have access to the SkyTitan (www.skytitan.net) telescopes in Wyoming and Texas.

In 2009, with professional astronomer Professor Quentin Parker of Macquarie University, we were successful in winning funding for a project entitled Space to Grow: The Faulkes Telescope and improving science engagement in schools. Funding was from the Australia Research Council (ARC) Linkage Grant scheme who also provided funding for a Post-Doctoral Research Fellow for three years. We worked with three educational jurisdictions in NSW to improve investigative science learning and teaching in the senior years of school. We worked with 37 schools using the Las Cumbres Observatory 2-metre class telescopes in Hawaii and Australia over a period of four years. Dr. Danaia was the nominated Post-Doctoral Fellow, a highly prestigious position in the eyes of the ARC with only two being appointed each year.

Michael Fitzgerald undertook his $\mathrm{PhD}$ by publication during this project, with the author and Dr. Lena Danaia as his supervisors. Dr. Fitzgerald published nine papers for the award of his doctorate (Fitzgerald, 2015) both in real science (Fitzgerald et al., 2015b; Fitzgerald et al., 2012; Frew et al., 2011) and in science education (Danaia et al., 2013; Danaia et al., 2012; Fitzgerald et al., 2017; Fitzgerald et al., 2016; Fitzgerald et al., 2015a; Fitzgerald et al., 2014). These are referenced in full at the end of this article to help readers locate, and read, the papers as well as to illustrate the imperative of communicating to others what one has done so that the same mistakes are not repeated. Las Cumbres Observatory Global Telescope (LCOGT) was a major partner in the investigation through providing both money and access to telescopes in its network. The project has been developed beyond the grant period and continues to the present day through our joint work in the Our Solar Siblings project

(www.oursolarsiblings.com, Fitzgerald et al., 2018) as an education partner in the LCOGT network.

In 2009 for the International Year of Astronomy, Matthew Howes and I undertook regular webcasts once a month for the first half of the year. Matthew set up a system where questions could be asked, objects requested etc., with answers being provided verbally by the author together with any images taken by the two CCD cameras displayed on the dynamic webpage. On the day after the webcast, the processed images were made available for download together with a podcast of the session. The early months of the year were very popular but interest waned and we curtailed the activity with the June broadcast when only four people came online.

In 2010, the telescope was in widespread use as an 
interest generating mechanism. Tim Boundy from JANET in the UK managed to link together students in Grades 5 and 6 form 40 elementary schools using video conferencing technology. The session was almost chaotic as they wanted to ask questions and see things in the southern sky.

In 2011, a low socio-economic status (SES) school district in Georgia, USA made approaches through their IT Director to get access. Additional materials that fitted the Science and Mathematics standards of that state had to be written. These were implemented by the teachers extending the cross-curriculum reach of the materials. Contact was via video-conferencing technology (Polycom) when students took control of the telescope via their computers. This project lasted for three years.

In 2012, we again broadcast the Transit of Venus and engaged with Australian schools over a video-conferencing link hosted by Polycom. The weather was problematic early and we missed first and second contacts, but managed to broadcast the third and fourth, again providing data timed to the millisecond. These data were shared with the Barekat Observatory in Israel for use by students in their Physics classes.

In the same year, we began a project in a rural area of Victoria, a state to the south of NSW and in remote schools in Western Australia. There, students and their teachers in their small isolated schools observed the night sky above both NSW using both the author's telescope, and Scott Mecca's SkyTitan telescope in Wyoming. This investigation provided data for a $\mathrm{PhD}$ thesis by Arthur Townsend 2015 with a follow up paper produced soon afterwards (Townsend et al., 2017). In 2012, we also became involved in addressing the opportunity gap through engaging low SES schools in Science, Technology, Engineering and Mathematics (STEM) education with a project called Indigenous Sky Stories. It foregrounded Aboriginal stories about the night sky to motivate all students in the 19 elementary schools that took part. This also became the subject of a Bachelor thesis (Ruddell, 2013) and led to a further publication in the literature (Ruddell et al., 2016).
The candidate is now undertaking his doctoral studies, by publication, in the same domain with many more schools currently participating in NSW, Victoria and Western Australia. Figure 12 shows a group of Grade 5 students with their art works constructed in class to illustrate the telling of four astronomical stories by an Aboriginal Elder.

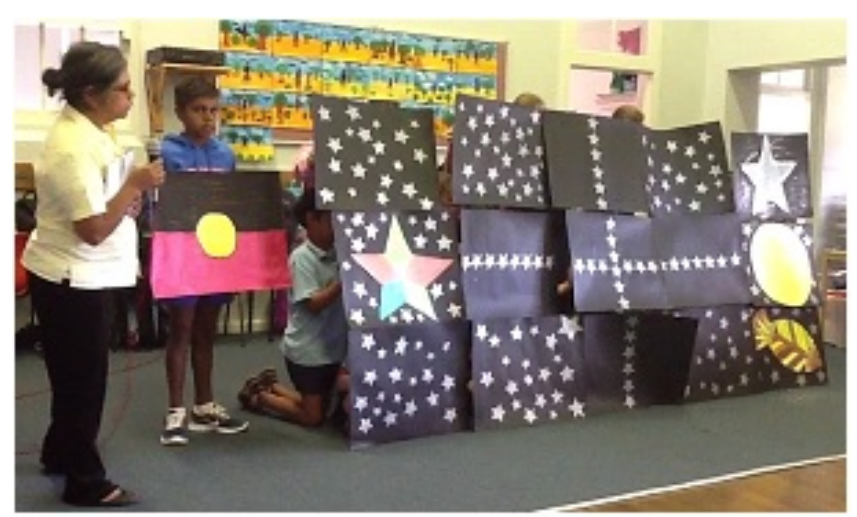

Figure 12. Year 5 students with their artworks illustrating the stories to students at school while the stories were told by a Wiradyuri Elder.

\section{Discussion}

The Charles Sturt University Remote Telescope project evolved as new hardware, software and operating systems became available. At its inception in 1995, it could only just barely have operated. At that time, only the Bradford Robotic Telescope and Telescopes in Education were operational. Neither of these two approaches could work in Australia. Alternatives had to be found. Thus, the project evolved in response to technological developments and our research questions. Successful applications for research grants allowed extensive investigation of the impacts on students and their teachers giving rise to several doctoral and Bachelor theses, many conference presentations and publications as well as the national teaching honours bestowed on Danaia and McKinnon.

Central to the success of the CSU Remote Telescope project was collaboration at a variety of levels with the many different people involved. At the author's university, collaboration between 
educators and IT specialists allowed the telescope to go online. As the project evolved, astronomers, who have a major interest in the "efficiency of photon-collecting time" became interested and learned from "us educators" that motivation and professional learning of the teachers were central to the success of any project. That is to say, astronomers are not at all interested in getting multiple images of common objects such as M16, NGC5128 or the Moon, each year, unless something scientifically interesting is happening. In education, it is not the astronomical image that is of interest to our research team(s). Rather, the prime directive for the author and the others involved is investigating the impact and motivation changes that are engendered, and the kindling of an interest in science, any science, in the student, which is the subject of our research.

Thus, collaboration between professional astronomers and educational researchers is essential if any project is to make an impact in educational circles. Both bring their deep understanding of different domains of knowledge to the enterprise. Astronomers seldom possess the relevant contextual knowledge of schools, teachers or students. Educators seldom possess the relevant technical and astronomical knowledge. The cooperative group can possess both.

The author's early mistakes demonstrated the absolute centrality of understanding the role that teacher professional learning (or professional development) plays in the outcomes of any project. It is of little use if the astronomer/researcher tells the teacher "how to do it" only once. Long-term professional-learning follow-up is required with all teachers. Not only that, professional learning is expensive. For example, in our ARC funded Space to Grow project worth AUD\$2.3 million, professional learning costs amounted to AUD\$1.7 million.

The same has also been true for the CSU Remote Telescope project. That is to say, the hardware and software cost relatively little while the time devoted to the teachers' learning, and attendant costs, are large comprising almost $90 \%$ of the total costs. Thus, good/great professional learning, I argue, is paramount and central to the success of any project in schools.

Moreover, all projects need a high-powered evaluation program before implementation. One of the major problems in any project is the danger of confirmation bias. After all, "we" have invested a great deal of time and money to acquire or to build the hardware. "We" want to see success. Unfortunately, this colours our interpretations of the data that "we" have collected or intend to collect.

The author has learned over a long career that it is often the unanticipated events that produce the most useful insights and the greatest opportunities to take the project to the next level and beyond. Importantly, embedded evaluation provides data for research students at the Bachelor, Master or Doctoral levels.

It is also important, and ethical, to publish the findings of the research BOTH negative and positive. The imperative of publishing both is clearly evident when one asks questions of the prior conditions that could have led to the outcomes contained in a journal article. The approach involves a clear application of Bayesian statistical approaches. Knowing simply that something is "statistically significant" is not enough. Reporting effect sizes (e.g., Cohen's d) is better. Describing the priors as well as the details of what has been done is best.

Our investigations with both Remote and Robotic Telescopes have helped provide evidence of a developmental progression from using remotely operated instruments with a helper at the telescope end through to the anonymous use of robotic telescopes for students to undertake deep astronomical investigations worthy of publication in the professional literature.

In our collaborative enterprises, we should all attempt to get to the students and their teachers early in their schooling at the developmentally appropriate level, using developmentally appropriate curriculum materials all of which are 
underpinned by the best professional learning.

The curriculum materials have to be created so that teachers do not perceive themselves as adding to their already inflated programs of work and workloads. The materials should be good enough, and preferably better, to replace something that is not particularly well done by existing materials. Moreover, it should motivate students and their teachers.

Collaboration across the world is thus key to take the RTSRE enterprise to the next level to achieve systemic change. The author hopes that the proliferation of the brilliant systems displayed at the RTSRE 2017 conference will also lift the research endeavour to the next level. I encourage all who read this to publish their findings. I also urge those who do not feel that they are qualified to undertake research into any of the domains referred to above to form partnerships with those who are. Inevitably, this involves collaboration.

The twenty years of our highly collaborative project have not only been highly productive from the instrumental perspective of research outputs, they have also been personally exciting, satisfying and mind-numbingly challenging at times leading to many sleepless nights! The outputs have included papers, conferences, research grants, and higher degree graduates. On the personal front, it is priceless when one sees a bored student approach their computer to get an image of "Saturnis" in the case of one young female Dutch student, and observe her jaw-dropping reaction and excitement to the image when it appeared on her screen in the Netherlands. Luckily, our microphone was muted.

\section{Acknowledgements}

I extend my profound thanks to the many people at Charles Sturt University including those in IT and in the Faculty of Education who became involved directly or indirectly, especially Mike Rebbechi, Tim Brown, and Anthony Oliver in IT. Amongst them are students in teacher education courses, and others who saw the potential of the ideas briefly covered here, supporting the project along the way both morally and, in some cases, financially. I also express my profound thanks to those research students who came with their own ideas and contributed not only to the research enterprise but also to the collegiality of the group. Many have now moved on to carve their own careers in Education and IT. In the IT domain, Andrew Mainwaring set up the original servers and website. Matthew Howes followed in the IT role. I thank both profoundly for their help. One researcher who deserves special mention is Dr. Lena Danaia. She mixed it with the author over 16 years. I wish them all well. I thank unreservedly all of the teachers and their students who undertook the projects and provided us with so much data and feedback for numerous publications and helped our research students to graduate.

\section{References}

Danaia, L. (2001). Students' alternative scientific conceptions: An intervention involving the Charles Sturt University Remote Telescope. BEd Honours Thesis. Bathurst: Charles Sturt University.

Danaia, L., Fitzgerald, M., and McKinnon, D. (2013). Students' perceptions of high school science: what has changed over the last decade? $R e$ search in Science Education, 43(4):1501-1515.

Danaia, L., McKinnon, D., Parker, Q., Fitzgerald, M., and Stenning, P. (2012). Space to grow: LCOGT. net and improving science engagement in schools. Astronomy Education Review, 11(1).

Danaia, L. and McKinnon, D. H. (2007). Common alternative astronomical conceptions encountered in junior secondary science classes: Why is this so? Astronomy Education Review, 6(2).

Danaia, L. J. (2006). Students' Experiences, Perceptions and Performance in Junior Secondary School Science: An Intervention Study Involving Astronomy and a Remote Telescope. PhD thesis, School of Teacher Education, Charles Sturt University. 
Fitzgerald, M., Danaia, L., and McKinnon, D. H. (2017). Barriers inhibiting inquiry-based science teaching and potential solutions: perceptions of positively inclined early adopters. Research in Science Education, pages 1-24.

Fitzgerald, M., McKinnon, D. H., and Danaia, L. (2015a). Inquiry-based educational design for large-scale high school astronomy projects using real telescopes. Journal of Science Education and Technology, 24(6):747-760.

Fitzgerald, M., McKinnon, D. H., Danaia, L., and Deehan, J. (2016). A large-scale inquiry-based astronomy intervention project: impact on students' content knowledge performance and views of their high school science classroom. Research in Science Education, 46(6):901-916.

Fitzgerald, M. T. (2015). Design principles, implementation and evaluation for inquiry-based astronomy: an investigation of the issues surrounding sufficient teacher professional development in large-scale astronomical initiatives. $\mathrm{PhD}$ thesis, Macquarie University, Faculty of Science and Engineering, Department of Physics and Astronomy.

Fitzgerald, M. T., Criss, J., Lukaszewicz, T., Frew, D. J., Catelan, M., Woodward, S., Danaia, L., and McKinnon, D. H. (2012). RR Lyrae stars in the globular cluster NGC 6101. Publications of the Astronomical Society of Australia, 29(1):72-77.

Fitzgerald, M. T., Hollow, R., Rebull, L. M., Danaia, L., and McKinnon, D. H. (2014). A review of high school level astronomy student research projects over the last two decades. Publications of the Astronomical Society of Australia, 31.

Fitzgerald, M. T., Inwood, L., McKinnon, D. H., Dias, W., Sacchi, M., Scott, B., Zolinski, M., Danaia, L., and Edwards, R. (2015b). Photometric and proper motion study of the neglected open cluster NGC 2215. The Astronomical Journal, 149(6):190.

Fitzgerald, M. T., McKinnon, D. H., Danaia, L., Cutts, R., Salimpour, S., and Sacchi, M.
(2018). Our Solar Siblings: A high school focused robotic telescope-based astronomy education project. In Fitzgerald, M. T., James, C. R., Buxner, S., and White, S., editors, Robotic Telescopes, Student Research, and Education Proceedings, volume 1(1), pages 217-231.

Fitzgerald, M. T., McKinnon, D. H., Danaia, L., and Woodward, S. (2011). Using smartphone camera technology to explore stellar parallax: Method, results, and reactions. Astronomy Education Review, 10(1).

Frew, D. J., Stanger, J., Fitzgerald, M., Parker, Q., Danaia, L., McKinnon, D., Guerrero, M. A., Hedberg, J., Hollow, R., An, Y., et al. (2011). K 1-6: an asymmetric planetary nebula with a binary central star. Publications of the Astronomical Society of Australia, 28(1):83-94.

McKinnon, D. and Geissinger, H. (2002). Interactive astronomy in elementary schools. Educational Technology \& Society, 5(1):124-128.

McKinnon, D. H. (2002). Astronomy in ANW. NVOX: Science Teachers' Journal of The Netherlands.

McKinnon, D. H. and Danaia, L. (2005). The eye observatory remote telescope project: practical astronomy for years 7,8 and 9. Research and Development report prepared for Department of Education Science and Training (DEST).

McKinnon, D. H., Danaia, L., and Deehan, J. (2017). The design of preservice primary teacher education science subjects: The emergence of an interactive educational design model. Journal of Astronomy and Earth Sciences Education, 4(1):1.

McKinnon, D. H., Geissinger, H., and Danaia, L. (2002). Helping them understand: Astronomy for Grades 5 and 6. Information Technology in Childhood Education Annual, 2002(1):263-275.

McKinnon, D. H. and Mainwaring, A. (2000). The Charles Sturt University remote telescope project: 
Astronomy for primary school students. Publications of the Astronomical Society of Australia, 17(2):125-128.

McKinnon, D. H. and Nolan, C. P. (2000). Cosmology on the Internet: Distance education for the gifted and talented. Publications of the Astronomical Society of Australia, 17(2):133-140.

Ruddell, N. (2013). Indigenous Sky Stories: A longitudinal case study of students' perceptions of, and performance in, primary school science. BEd Honours Thesis. Bathurst: Charles Sturt University.

Ruddell, N., Danaia, L., and McKinnon, D. (2016). Indigenous Sky Stories: Reframing How we Introduce Primary School Students to Astronomy-a Type II Case Study of Implementation. The Australian Journal of Indigenous Education, 45(2):170-180.

Stepans, J. (1996). Targeting students' science misconceptions: Physical science concepts using the conceptual change model. Idea Factory.

Townsend, A. (2015). Educative curricula and improving the science PCK of teachers in middle school settings in rural and remote Australia. $\mathrm{PhD}$ thesis, School of Education, Edith Cowan University.

Townsend, A., McKinnon, D. H., Fitzgerald, M. T., Morris, J., and Lummis, G. (2017). Educative curricula and PCK development driven by STEM professional learning in rural and remote schools: a longitudinal Type IV Case Study. International Journal of Innovation in Science and Mathematics Education (formerly CAL-laborate International), 24(4).

Trueblood, M. and Genet, R. (1985). Microcomputer control of telescopes. Richmond: WillmannBell, 1985. 